\title{
ESCOAMENTO PLÁSTICO E COMPORTAMENTO TENSÃO-DEFORMAÇÃO DE SOLOS CIMENTADOS
}

\author{
D. S. S. Moura \\ darciasamia@hotmail.com \\ R. N. F. Severo \\ Professor do Departamento de Construção Civil do CEFET-RN \\ ricardoflores@cefetrn.br \\ H. G. Carvalho Junior ${ }^{1}$ \\ henriquejunior_5@hotmail.com \\ O. C. Macedo Neto \\ ovidiocabral@hotmail.com
}

\section{RESUMO}

Nas últimas décadas vários trabalhos vêm sendo realizados no sentido de compreender o comportamento dos solos com cimentação entre as partículas. Estudos dessa natureza foram realizados em solos naturais e artificiais. É muito comum a ocorrência de solos cimentados naturalmente em ambientes tropicais. O estudo desses solos se torna complexo pela dificuldade de obtenção de amostras e pela sua variabilidade espacial. Assim, para avaliar o efeito de agentes que controlam o comportamento desses solos tem sido freqüente a utilização de solos artificialmente cimentados. O litoral do estado do Rio Grande do Norte apresenta uma formação geológica presente em grande parte da região Nordeste, a Formação Barreiras que é constituída por solos naturalmente cimentados por óxido de ferro devido ao processo de laterização, comum em climas tropicais. Com vistas a estudar o comportamento mecânico dos solos cimentados dessa formação, foram realizados por Severo (2005), ensaios de cisalhamento direto em amostras indeformadas, e cimentadas naturalmente da Formação Barreiras. A análise desse e de outros trabalhos publicados permitiu a formação de um arcabouço conceitual do comportamento idealizado dos solos cimentados: quanto maior a cimentação maior a resistência e a rigidez dos mesmos. Nesse sentido essa pesquisa visa dar continuidade e preencher uma lacuna existente a respeito do conhecimento do efeito da porosidade (grau de compactação) e do grau de cimentação no comportamento das ligações entre as partículas. Esse estudo foi feito através da realização de ensaios de compressão uniaxiais não confinados convencionais em solos da Formação Barreiras, cimentados artificialmente, utilizando-se amostras preparadas em laboratório, com vistas a eliminar os efeitos de heterogeneidade encontrados nos solos naturais e devido à facilidade de confecção das amostras. O conhecimento das características tensãodeformação de solos cimentados é importante em vários problemas tratados na Engenharia Geotécnica, principalmente aqueles ligados à estabilidade de encostas e de taludes de corte em estradas. Os resultados dos ensaios mostraram que para um dado teor de cimento a resistência aumenta com o aumento do peso específico seco do solo, o solo mostra uma tendência de crescimento da resistência com o aumento da energia de compactação e conseqüente diminuição do índice de vazios.

PALAVRAS-CHAVE: instruções Solos cimentados, comportamento tensão-deformação, Formação Barreira. 


\section{ESCOAMENTO PLÁSTICO E COMPORTAMENTO TENSÃO-DEFORMAÇÃO DE SOLOS CIMENTADOS}

\section{INTRODUÇÃO}

O comportamento tensão-deformação, a rigidez e a resistência ao cisalhamento de solos cimentados variam com a magnitude e o tipo de ligação entre as partículas. O efeito da cimentação assume maior importância sob baixos níveis de tensão, onde a coesão efetiva exerce uma importante função nas obras de terra, sobretudo na estabilidade superficial de taludes. É freqüente a existência de encostas e taludes de corte íngremes (quase verticais) cuja estabilidade é mantida pelas ligações entre partículas. No entanto, uma instabilização súbita pode ocorrer caso ocorra a quebra dessas ligações.

Nesse sentido nossa pesquisa trata de um estudo experimental do comportamento de solos com cimentação artificial e natural através da realização de ensaios de compressão uniaxial com o objetivo de analisar os aspectos tensão-deformação e a resistência ao cisalhamento desses solos. Inicialmente estudaram-se amostras cimentadas artificialmente a fim de analisar o efeito da intensidade da cimentação sobre o comportamento mecânico dos solos, devido a facilidade de obtenção das amostras e para minimizar os efeitos da heterogeneidade dos solos lateríticos da Formação Barreiras.

A amostra de solo empregada nesse estudo foi proveniente da Formação Barreiras, coletada na região costeira do Rio Grande do Norte, no município de Tibau do Sul - RN, localizado sessenta quilômetros ao sul da cidade do Natal, em áreas de empréstimos já estudadas anteriormente por Chaves (1979). Estudos realizados nessa área indicam que a cimentação entre as partículas desenvolve influência positiva na estabilidade de taludes que formam falésias praticamente verticais na região (Silva, 2003; Santos Jr., et. al., 2004c; Santos Jr., et al 2005; Severo, 2005), no entanto a quantificação dessa influência ainda necessita de estudos detalhados.

Este estudo, portanto, têm dois objetivos: o primeiro é de natureza científica, através da compreensão do efeito das ligações entre as partículas no comportamento geomecânico de solos cimentados. O segundo tem implicações regionais, uma vez que o solo a ser estudado (Formação Barreiras) constitui-se em importante unidade geológica presente em todo o litoral Nordestino, se estendendo do Ceará a Bahia. Assim, a compressão detalhada do comportamento tensão-deformação desse solo poderá contribuir para a solução de problemas de estabilidade de taludes, escavações e de fundações.

\section{METODOLOGIA ADOTADA}

Nosso trabalho possui natureza experimental, sendo desenvolvido através da realização de ensaios sobre amostras de solo preparadas em laboratório com cimentação artificial. Os ensaios foram realizados no Laboratório de Mecânica dos Solos do CEFET-RN.

A primeira parte do trabalho consistiu na identificação e caracterização da amostra de solo e do cimento utilizado na mistura. A água foi a fornecida normalmente pela companhia de água e esgotos do RN. 
O cimento utilizado foi do tipo CP II - 32, com suas características físicas e químicas dentro das normas.

O solo usado na pesquisa apresenta $88 \%$ de areia, $8 \%$ de silte e $4 \%$ de argila. Possui limite de liquidez de $28 \%$ e índice de plasticidade de $7 \%$. A densidade real dos sólidos Gs é igual a 2,67. No Sistema Unificado de Classificação dos Solo (SUCS) o solo estudado foi classificado como SC (areia argilosa).

Na segunda parte do trabalho foram realizados ensaios de resistência a compressão simples em amostras de misturas de solo e cimento de um solo laterizado da Formação Barreiras situada na região do município de Tibau do Sul - RN.

Foram realizados ensaios em amostras com 2\%, 5\% e 10\% de cimento. As amostras foram compactadas em quatro camadas por meio da aplicação de golpes de um soquete metálico padronizado. Para avaliar o efeito da densidade (grau de compactação) as amostras foram preparadas com três energias distintas, com 10, 30 e 60 golpes por camada.

As amostras (CPs) foram curadas no ambiente do laboratório sob uma temperatura média de $25^{\circ} \mathrm{C}$ e umidade do ar de $65 \%$ durante 28 dias.

Decorrido este tempo os corpos de prova (CPs) foram rompidos em uma prensa computadorizada com velocidade controlada de $0,5 \mathrm{~mm} /$ minuto. Na Figura 1 é mostrada a seqüência de atividades para realização dos ensaios.

\section{ANÁLISE E APRESENTAÇÃO DOS RESULTADOS}

Os ensaios de cisalhamento por compressão não confinada foram realizados em 46 amostras, sendo 23 CPs rompidos na umidade natural e 23 em condições inundadas, permanecendo as 72 horas anteriores ao rompimento imersos em água. A umidade natural média é menor do que $1 \%$ para todas as amostras e a umidade na condição inundada varia entre $11 \%$ e $24 \%$ dependendo do grau de compactação dos corpos de prova. Quanto menor a porosidade menor a umidade gravimétrica.

Em conformidade com os resultados obtidos toma-se conhecimento de características tensão-deformação-tempo de solos cimentados naturalmente e assim pode-se auxiliar na resolução de diversos problemas tratados na Engenharia Geotécnica; por exemplo, aqueles ligados a estabilidade de taludes em solos residuais e sedimentares. Tais características serão apresentadas no decorrer desse item.

\subsection{Efeito da Inundação Sobre a Resistência à Compressão do Solo:}

a) Teor de cimento: $2 \%$

O Gráfico da Figura 2 (Peso especifico aparente seco X Resistência a compressão não confinada) apresenta os resultados das amostras moldadas com $2 \%$ de cimento e variados graus de compactação (depende do número de golpes, 10, 30 ou 60 e da energia de compactação aplicada em cada golpe). As amostras em azul foram rompidas na condição inundada e as vermelhas na umidade natural. 


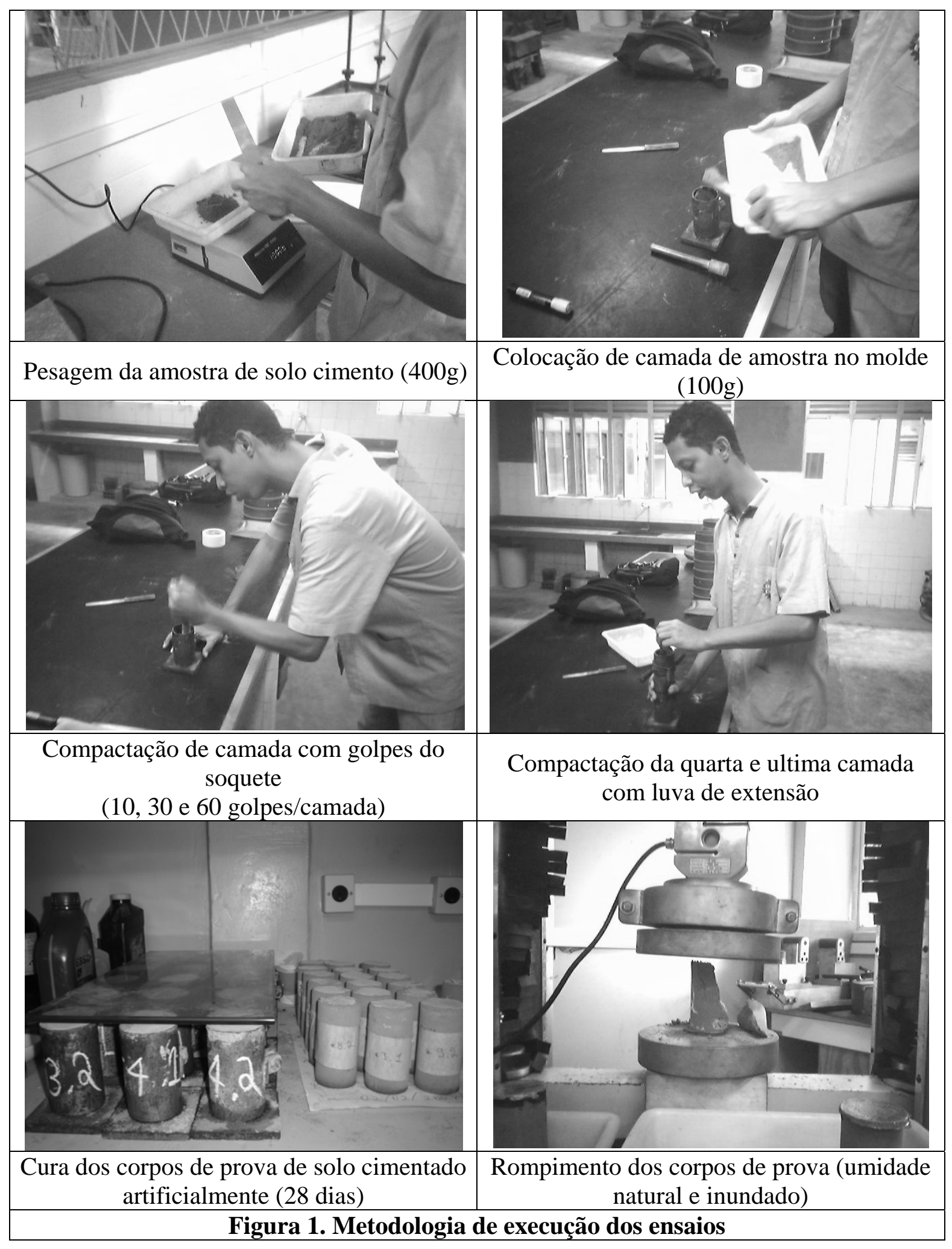




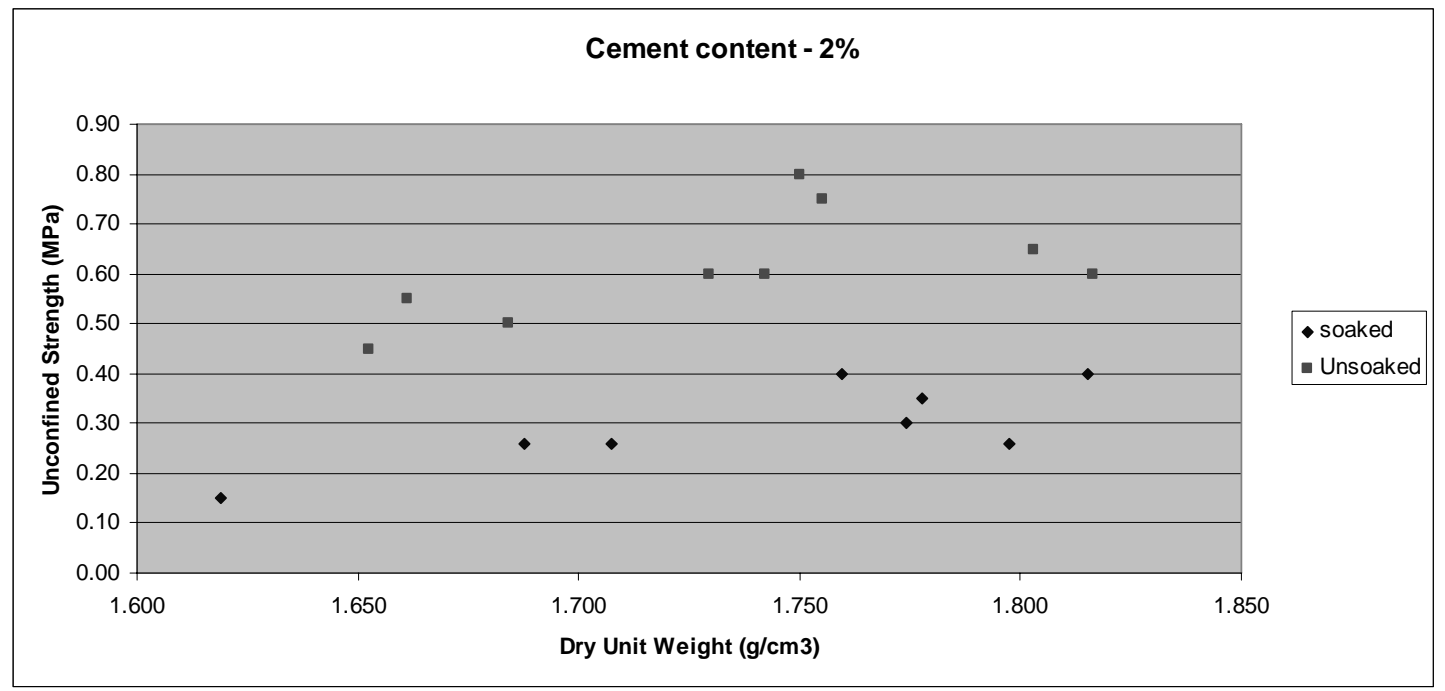

Figura 2. Teor de cimento de $2 \%$

Verifica-se que a resistência aumenta com o aumento do peso específico aparente seco do solo (ou com a energia de compactação) tanto para as amostras inundadas como para as amostras secas. As amostras inundadas apresentam resistência inferior àquelas obtidas nos ensaios secos, ou seja, a diminuição da sucção provocada pela inundação das amostras provoca redução da resistência.

b) Teor de cimento: $5 \%$

O Gráfico da Figura 3 (Peso especifico aparente seco X Resistência a compressão não confinada) apresenta os resultados das amostras moldadas com $5 \%$ de cimento e variados graus de compactação.

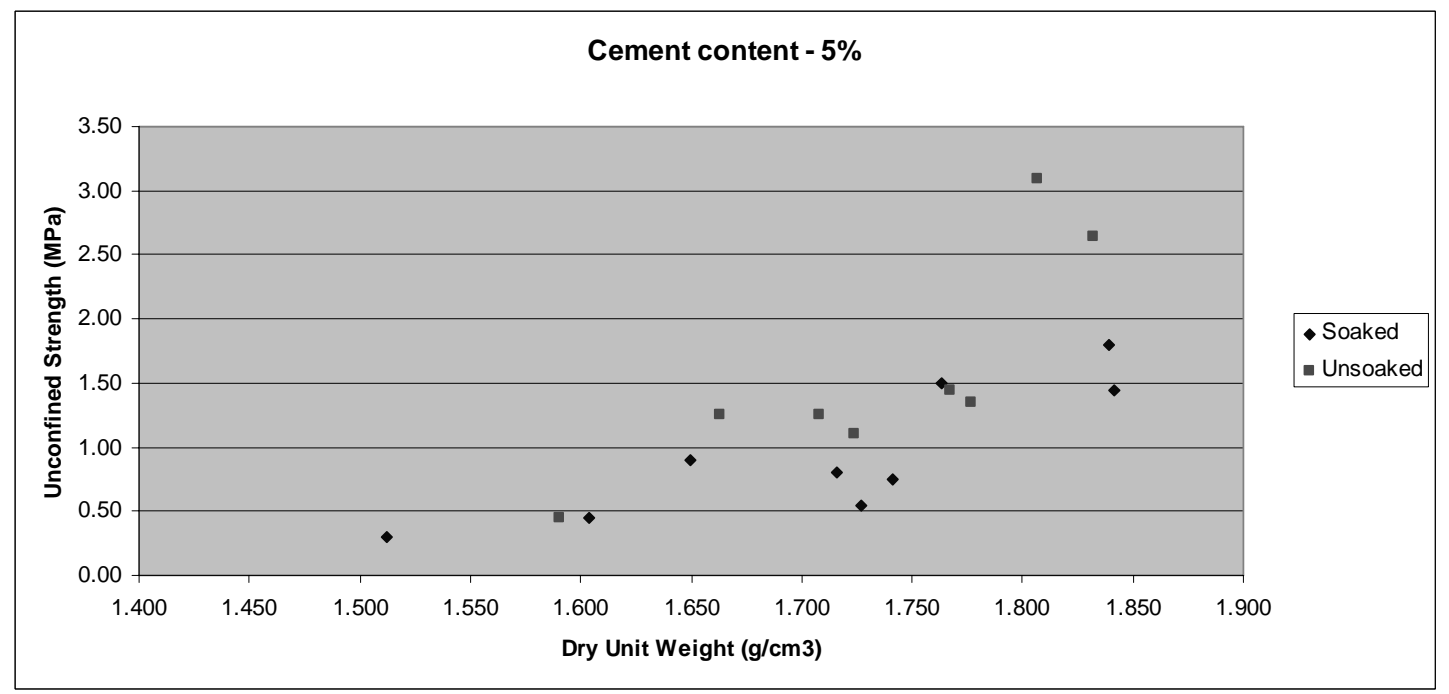

Figura 3. Teor de cimento de $5 \%$

Os resultados para 5\% de cimento mostraram uma tendência mais efetiva do crescimento da resistência com o aumento da energia de compactação comparativamente com os 
mostrados nas amostras com 2\% de cimento. Por outro lado, a sucção parece afetar menos a resistência dos solos com 5\% de cimento.

c) Teor de cimento: $10 \%$

O Gráfico da Figura 4 (Peso especifico aparente seco X Resistência a compressão não confinada) apresenta os resultados das amostras moldadas com $10 \%$ de cimento e variados graus de compactação.

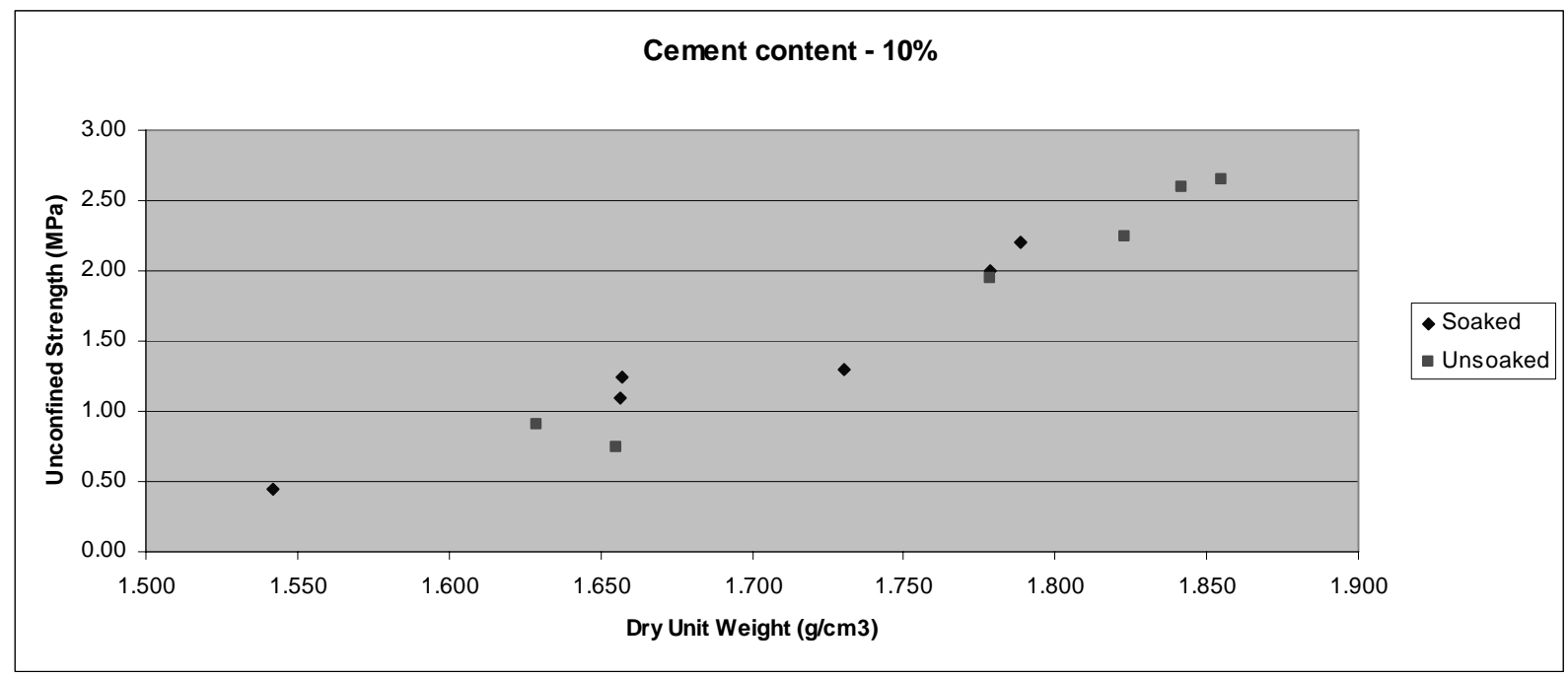

Figura 4. Teor de cimento de $10 \%$

O solo cimentado artificialmente apresenta aumento da resistência com o aumento da energia de compactação.

A sucção não afeta a resistência das amostras com $10 \%$ de cimento. Nesse caso o efeito da cimentação é mais importante que o da sucção no comportamento das amostras.

\subsection{Efeito da Inundação Sobre a Resistência à Compressão do Solo}

a) Amostras inundadas

O Gráfico da Figura 5 (Peso especifico aparente seco X Resistência a compressão não confinada) apresenta os resultados das amostras rompidas na condição inundada com teores de cimento de 2\%, 5\% e 10\% e variados graus de compactação. 


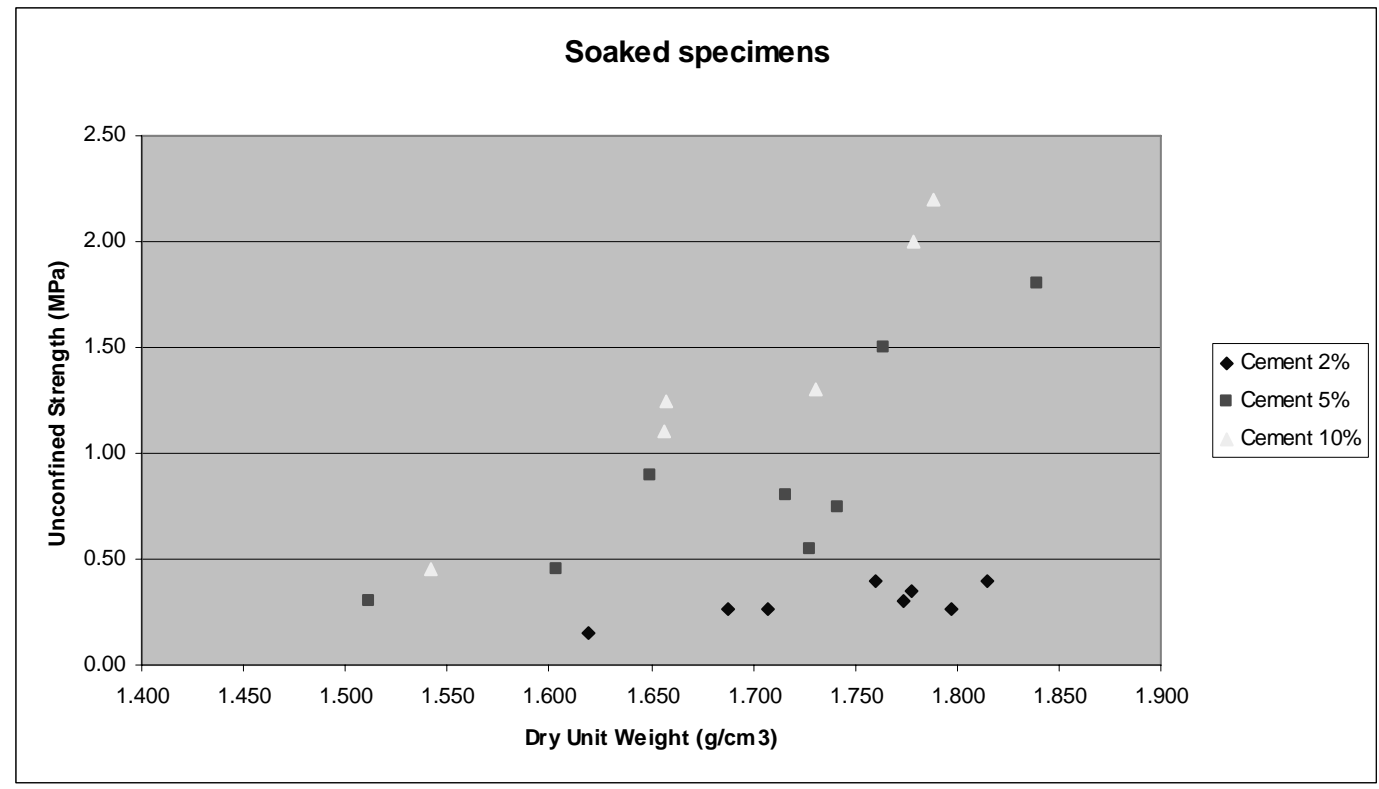

Figura 5 - Corpos de prova (CPs) na condição inundada

A resistência aumenta com o aumento do teor de cimento. Esse aumento é mais expressivo para valores mais elevados de peso específico seco (maior energia de compactação).

b) Amostras não inundadas

O Gráfico da Figura 6 (Peso especifico aparente seco X Resistência a compressão não confinada) apresenta os resultados das amostras rompidas na condição não-inundada com teores de cimento de $2 \%$, 5\% e $10 \%$ e variados graus de compactação.

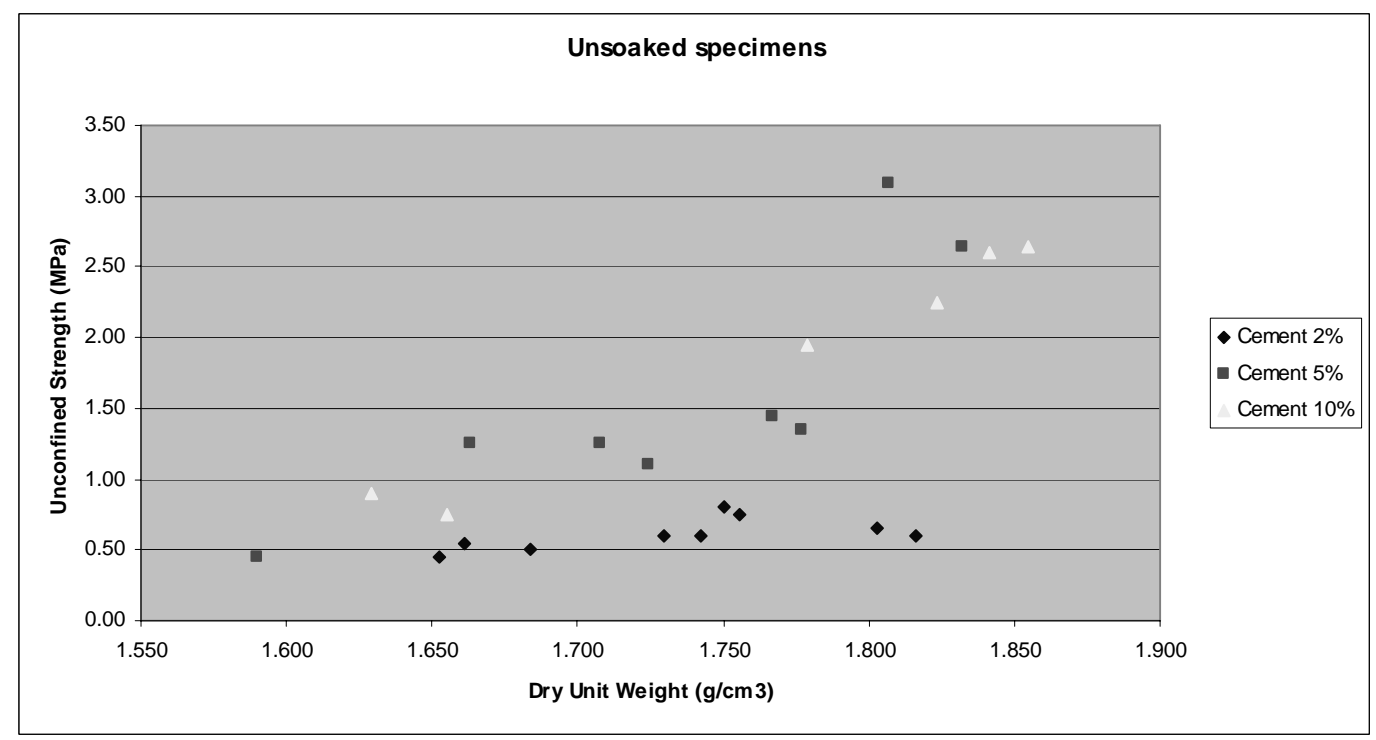

Figura 6 - Corpos de prova (CPs) na condição não-inundada

Esses resultados apresentaram maior dispersão que os das amostras inundadas. Os valores obtidos para as amostras moldadas com $5 \%$ e $10 \%$ são da mesma ordem de grandeza, o que pode sugerir a confirmação da observação de Consoli et al. (2007) item 2, que para um 
dado peso especifico aparente seco, geralmente um aumento na resistência é observado com o aumento do teor de cimento até um valor máximo alcançado, após o qual a resistência decresce.

\subsection{Variação das características físicas das amostras}

Os Gráficos das Figuras 7 e 8 apresentam os resultados da variação do peso específico aparente seco com a energia de compactação e da Variação do índice de vazios com a energia de compactação, respectivamente. Onde se verifica que quanto maior a energia de compactação maior o peso específico aparente seco e menor o índice de vazios e conseqüentemente a porosidade.

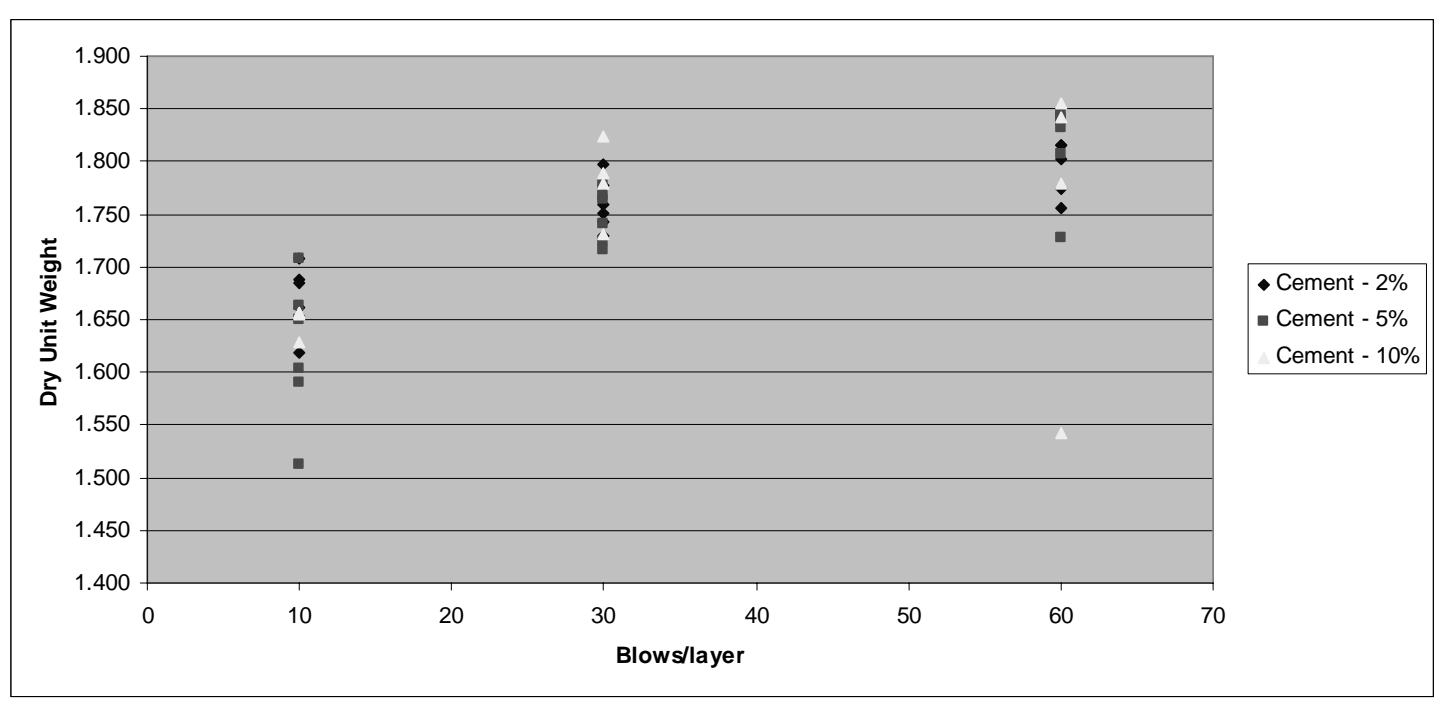

Figura 7. Variação do peso específico aparente seco com a energia de compactação

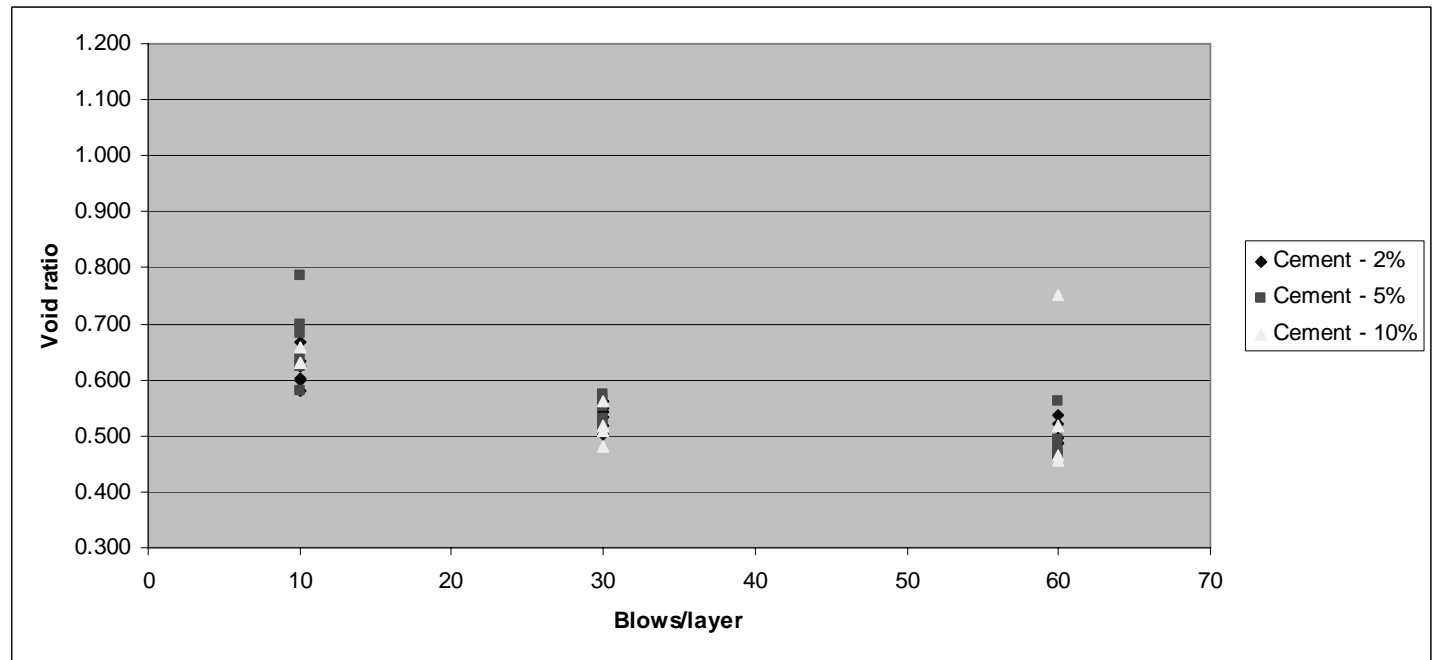

Figura 8. Variação do índice de vazios com a energia de compactação 


\section{CONCLUSÕES}

A partir da análise detalhada dos dados, conclui-se que: os resultados dos ensaios mostraram que para um dado teor de cimento a resistência aumenta com o aumento do peso específico seco do solo. O solo mostra uma tendência de crescimento da resistência com o aumento da energia de compactação e conseqüente diminuição do índice de vazios.

A partir de um determinado teor de cimento (5\% nesse caso) a resistência aumenta significativamente com o aumento da proporção de cimento na mistura e aumento do peso específico seco. O efeito da cimentação é mais pronunciado, em termos de ganho de resistência devido ao aumento do teor de cimento, para valores mais baixos de índice de vazios.

Para um dado peso especifico aparente seco, geralmente um aumento na resistência é observado com o aumento do teor de cimento até um valor máximo alcançado, após o qual a resistência estabiliza ou decresce (no caso entre 5\% e 10\%). Ou seja, no caso de melhoramento de solos para pavimentos basta acrescentar 5\% de cimento ao invés de $10 \%$ para esse solo específico.

A sucção parece afetar menos a resistência dos solos com 5\% de cimento, do que os que apresentam apenas $2 \%$. A sucção não afeta a resistência das amostras com $10 \%$ de cimento. Nesse caso o efeito da cimentação é mais importante que o da sucção no comportamento das amostras.

Os dados obtidos dos ensaios de laboratório confirmam a observação de Consoli et al (2007) para solos cimentados artificialmente, que afirma que a relação índice de vazios/cimento definida como a razão entre a porosidade e o teor de cimento na mistura compactada é mais apropriada para avaliar a resistência a compressão não confinada do que a relação água/cimento.

\section{REFERÊNCIAS BIBLIOGRÁFICAS}

Chaves, L.F.M. (1979). Propriedades Químicas e Mineralógicas de Três Solos Vermelhos Tropicais do Estado do Rio Grande do Norte.. Dissertação (Mestrado em Geotecnia) - UFPB, Campina Grande.

Consoli, N. C.; Foppa, D.; Festugato L.; Heineck, K. S. Key Parameters for Strenght Control of Articialy Cemented Soils. Journal of Geotechnical and Geoenvinmental Engineering. ASCE (2007)

Das, B. M.; Yen, S. C.; Dass, R. N. Brazilian Tensile Strength Test f Lightly Cemented Samples. Canadian Geotechnical Journal, vol. 32, pp. 166-171, 1995.

Leroueil, S.; Vaughan, P. R. The General and Congruent Effects of Structure in Natural Soils and Weak Rocks. Géotechnique, vol. 40, No. 3, pp. 467-488, 1990.

Lee, I. K; Coop, M. R. The Intrinsic Behavior of a Decomposed Granite Soil. Géotechnique, vol 45, №ํ1, 117-130, 1995.

Rotta, G. V.; Prietto, P. D. M.; Consoli, N. C.; Gehling, W. Y. Y. Influência do Índice de Vazios da Matriz Cimentante no Comportamento Mecânico dos Solos Cimentados. Solos e Rochas, vol 24, № 1, 23-41, 2001. 
Santos Jr., O. F. Estudo Experimental do Comportamento de um Solo Residual Submetido a Variações Cíclicas de Poro-pressão. Tese de Doutorado, COPPEUFRJ, 1996.

Santos Jr., O. F.; Lacerda, W. A.; Ehrlich, M. Escoamento Plástico e Comportamento Tensão - Deformação do Solo Residual da Encosta do Soberbo - Rio de Janeiro. Solos e Rochas, vol 27, № 3 , 203-213, 2004a.

Santos Jr., O. F.; Lacerda, W. A.; Ehrlich, M. Comportamento do Solo Residual da Encosta do Soberbo (Rio de Janeiro) em Ensaios Triaxiais com Variações Cíclicas de Poro-pressão. Solos e Rochas, vol 27, № 2, 117-130, 2004 b.

Santos Jr., O. F.; Scudelari, A. C.; Amaral, R. F.: Geotechnical Properties of Tertiary Sediments and Failure Mechanisms of a Sea Cliff in the State of Rio Grande do Norte, North East Brazil. IV International Symposium on Landslides, Rio de Janeiro, Vol. 1, 729-733, 2004c.

Santos Jr, O. F.; Severo, R. N. F.; Freitas Neto, O.; França, F. A. N.: Análise da Esabilidade nas Falésias entre Tibau do Sul e Pipa - RN. IV Conferência Brasileira Sobre Estabilidade de Encostas, Salvador.Vol. I, 487-496, 2005

Severo, R. F.: Análise da Estabilidade das Falésias entre Tibau do Sul e Pipa - RN. Dissertação de Mestrado, Universidade Federal do Rio Grande do Norte, Programa de Pós-graduação em Engenharia Sanitária, 2005.

Silva, W. S.: Estudo da dinâmica superficial e geotécnica das falésias do município de Tibau do Sul - Litoral Oriental do RN. Dissertação de Mestrado. Universidade Federal do Rio Grande do Norte. Programa de Pós-graduação em Engenharia Sanitária, 2003

Vaughan, P. R. Mechanical and Hydraulic Properties of Tropical Lateritic and Saprolitic Soils, Particularly as Related to their Structure and Mineral Components. First International Conference On Geomechanics In Tropical Lateritic And Saprolitic Soils, Tropical’s 85, Brasília, vol. 3, 231-263, 1985. 